\title{
Impact of catheter contact angle on lesion formation and durability of pulmonary vein isolation
}

\author{
Masayuki Ohta ${ }^{1}$, Kentaro Hayashi ${ }^{1}$, Hiroyuki Sato ${ }^{1}$, Takahiro Noto ${ }^{1}$, Kandoh Kawahatsu ${ }^{1}$, \\ Masaya Katagiri ${ }^{1}$, Tomohiro Mita ${ }^{1}$, Yoshio Kazuno ${ }^{1}$, Shunsuke Sasaki ${ }^{1}$, Takahiro Doi ${ }^{1}$, \\ Mitsugu Hirokami ${ }^{1}$, Shigemichi Tanaka ${ }^{1}$, and Satoshi Yuda ${ }^{1}$ \\ ${ }^{1}$ Teine Keijinkai Hospital
}

January 29, 2021

\begin{abstract}
Introduction Little is known on the effect of catheter contact angle on lesion formation and durability of pulmonary vein isolation (PVI). Methods Both in vitro experiment and retrospective observational study were conducted. For in vitro experiment, radiofrequency lesions were created on explanted swine hearts in three different catheter contact angles $\left(0^{\circ}, 45^{\circ}\right.$, and $\left.90^{\circ}\right)$. In the retrospective observational study, we assessed patients who had undergone repeat catheter ablation due to atrial fibrillation recurrence after initial PVI. When pulmonary vein (PV) reconnection was observed, we analyzed the previous ablation points within and without the gap area. The gap areas were defined where ablation had changed the PV activation sequence or eliminated the PV potential in the repeat session. Results In the in vitro experiment, lesion width was the smallest (5.3 \pm $0.4 \mathrm{~mm}$ ) in perpendicular contact compared to $0^{\circ}$ (vs $5.8 \pm 0.5 \mathrm{~mm}, \mathrm{p}=0.040$ ) and $45^{\circ}$ (vs $6.4 \pm 0.4 \mathrm{~mm}, \mathrm{p}<0.001$ ). In the retrospective observational study, we assessed 666 tags of 16 patients with PV reconnections, and 60 tags were in the gap area. Tags in the gap area had longer interlesion distance (odds ratio $[\mathrm{OR}] 1.49, \mathrm{p}<0.001$ ), greater contact force variability (OR 1.03, $\mathrm{p}=0.008$ ), and higher rate of perpendicular contact (OR 3.26, p < 0.001) on multivariate analysis. Conclusion Perpendicular contact was associated with a smaller lesion and higher rate of PV reconnection.
\end{abstract}

Impact of catheter contact angle on lesion formation and durability of pulmonary vein isolation

Masayuki Ohta, MD; Kentaro Hayashi, MD; Hiroyuki Sato, MD; Takahiro Noto, MD; Kandoh Kawahatsu, MD; Masaya Katagiri, MD; Tomohiro Mita, MD, PhD; Yoshio Kazuno, MD; Shunsuke Sasaki, MD, PhD; Takahiro Doi, MD, PhD; Mitsugu Hirokami, MD; Shigemichi Tanaka, MD, PhD; Satoshi Yuda, MD, PhD

Affiliations: Department of Cardiology, Teine Keijinkai Hospital, Hokkaido, Japan.

Disclosures: All authors declare no conflict of interest.

Funding: (None)

Address for correspondence: Masayuki Ohta

Department of Cardiology, Teine Keijinkai Hospital, 1-40, 1 jo 12-chome, Maeda, Teine-ku, Sapporo, Hokkaido, 006-0811, Japan.

Fax: 81-011-685-2998

Tel: 81-011-681-8111

E-mail:masayukidakido@gmail.com

Structured Abstract 


\section{Introduction}

Little is known on the effect of catheter contact angle on lesion formation and durability of pulmonary vein isolation (PVI).

\section{Methods}

Both in vitro experiment and retrospective observational study were conducted. For in vitro experiment, radiofrequency lesions were created on explanted swine hearts in three different catheter contact angles $\left(0^{\circ}\right.$, $45^{\circ}$, and $90^{\circ}$ ). In the retrospective observational study, we assessed patients who had undergone repeat catheter ablation due to atrial fibrillation recurrence after initial PVI. When pulmonary vein (PV) reconnection was observed, we analyzed the previous ablation points within and without the gap area. The gap areas were where ablation had changed the PV activation sequence or eliminated the PV potential in the repeat session.

\section{Results}

In the in vitro experiment, lesion width was the smallest $(5.3 \pm 0.4 \mathrm{~mm})$ in perpendicular contact compared to $0^{\circ}$ (vs $5.8 \pm 0.5 \mathrm{~mm}, \mathrm{p}=0.040$ ) and $45^{\circ}$ (vs $6.4 \pm 0.4 \mathrm{~mm}, \mathrm{p}<0.001$ ). In the retrospective observational study, we assessed 666 tags of 16 patients with PV reconnections, and 60 tags were in the gap area. Tags in the gap area had longer interlesion distance (odds ratio $[\mathrm{OR}] 1.49, \mathrm{p}<0.001$ ), greater contact force variability (OR 1.03, $\mathrm{p}=0.008)$, and higher rate of perpendicular contact (OR 3.26, $\mathrm{p}<0.001)$ on multivariate analysis.

\section{Conclusion}

Perpendicular contact was associated with a smaller lesion and higher rate of PV reconnection.

Keywords: Atrial fibrillation, catheter ablation, pulmonary vein isolation, catheter contact orientation, perpendicular contact

\section{Abbreviations list}

AF Atrial fibrillation

AI Ablation index

CF Contact-force

EACTS European Association of Cardio-Thoracic Surgery

FTI Force-time integral

LA Left atrial

PV Pulmonary vein

PVI Pulmonary vein isolation

ROC Receiver operating characteristic curve

\section{Introduction}

Pulmonary vein isolation (PVI) is a cornerstone therapy in catheter ablation of atrial fibrillation (AF) (1). Studies on AF recurrence rates after initial ablation procedures have been variable, ranging from $20 \%$ to $80 \%$ in several studies, and $20 \%-50 \%$ of patients require a repeat ablation procedure to achieve sinus rhythm during long-term follow-up (2,3). The left atrial (LA)-pulmonary vein (PV) reconnection after initial PVI is one of the main causes of AF recurrence. (4) Therefore, durable lesion formation is important in preventing recurrences of $\mathrm{AF}$.

Three-dimensional mapping systems, irrigation catheters, and contact-force (CF) sensing catheter have been developed to improve lesion durability. Furthermore, force-time integral (FTI) and other lesion indexing 
algorithms, including ablation index (AI), have been used as surrogates for radiofrequency (RF) dose and lesion size. However, LA-PV reconnection remains unclear with these instruments (5-7).

Catheter stability can be a factor of durable lesion formation beyond FTI or AI. Makimoto et al. supposed that, even if the mean CF applied is within the target range, a large variability of the actual CF value during $\mathrm{RF}$ application suggests catheter instability (8). Ullah et al. have also shown larger CF variability resulting in smaller impedance drop (9). Moreover, they showed several factors associated with lesser impedance drop: catheter CF variability $>5 \mathrm{~g}$, catheter drift $>3.5 \mathrm{~mm}$, sinus rhythm, and perpendicular contact (9). However, little is known about the effect of catheter contact angle against the myocardium on lesion formation and durability of PVI.

This study aimed to evaluate the impact of catheter contact angle on lesion formation and durability of PVI.

\section{Methods}

We conducted both in vitro experiment and retrospective observational study. The retrospective analysis was in accordance with the "Declaration of Helsinki" and approved by the Ethics Committee of Teine Keijinkai Hospital (2-020132-00).

\section{In vitro experiments}

The swine's heart ventricular tissue was dissected and pinned to a tissue holder that was fixed in a saline bath. Using a CARTO system (Biosense Webster, Inc.) and a ThermoCool SmartTouch irrigated-tip CF sensing RF ablation catheter (Biosense Webster, Inc.), RF lesions were created with ablation power of 20 $\mathrm{W}$ for $15 \mathrm{~s}$ with saline $8-\mathrm{mL} / \mathrm{min}$ irrigation in two different catheter CFs $(5 \mathrm{~g}$ and $10 \mathrm{~g})$ and three different catheter contact angles $\left(0^{\circ}, 45^{\circ}\right.$, and $\left.90^{\circ}\right)$ (Fig. 1A). Five radiofrequency applications were applied under each condition, and 30 lesions were created. The lesions were sectioned along their major axis, and widths and depths were measured (Fig. 1B). We also investigated each FTI, AI, impedance before RF application (preimpedance), impedance after RF application (post-impedance), and impedance change (impedance drop).

\section{Retrospective observation study}

\section{Patient population}

We included 27 consecutive patients who underwent repeat catheter ablation due to AF recurrence after initial PVI using the CARTO system and VisiTag ${ }^{\mathrm{TM}}$ module from October 1, 2017, to August 31, 2019. All patients provided written informed consent before the procedures.

\section{Catheter ablation procedure}

All patients underwent the procedure under sedation. Transesophageal echocardiography was performed to rule out thrombus in the left atrium before the procedure. After dual transseptal puncture, 3D electroanatomical maps of the LA and PVs were reconstructed with a PentaRay (Biosense Webster, Inc.) in each session. In the first session, extensive encircling PVI was performed by point-by-point RF application using a ThermoCool SmartTouch irrigated-tip CF sensing RF ablation catheter (Biosense Webster, Inc.). Ablation lesion was manually tagged immediately after the catheter was stabilized to record the catheter position and the vector arrows showing actual angle of catheter tip to the tissue (Fig. 2B). VisiTag ${ }^{\mathrm{TM}}$ was also annotated automatically on the lesion, based on the location stability setting of $3 \mathrm{~mm}$ for $10 \mathrm{~s}$ with respiration adjustment and without force over time or impedance drop filters. When first-pass isolation was not achieved, reablation would be applied at the sites with conduction gap until both exit and entrance blocks were achieved. In the repeat session, RF ablation was applied at the sites with conduction gap if LA-PV reconnection was observed.

\section{Study measurements}

We assessed the previous RF application of patients with LA-PV reconnection confirmed in the repeat session. The tags were excluded from the analysis if two or more VisiTags were annotated with one RF application. The PVI line of each ipsilateral PV was divided into ten areas by anterior/posterior and 
roof/superior/carina/inferior/bottom (Fig. 2A). The gap areas were defined where RF ablation had changed the PV activation sequence or eliminated the PV potential in the repeat session. Perpendicular contact was defined when the angle between the vertical line to the ablation catheter and the vector arrow was $>60^{\circ}$ (Fig. 2B). We investigated all VisiTag ${ }^{\mathrm{TM}}$ information of initial PVI: ablation time, ablation power, catheter temperature, CF, FTI, AI, generator impedance, and maximum distance to the adjacent tags (Dmax) (Fig. 2C). CF variability was defined as the difference between maximum and minimum CF.

\section{Statistical analysis}

In in vitro experiments, to compare three different catheter contact angles, we performed the one-way analysis of variance. We also performed Student's t-test to compare two groups. In the retrospective analysis of PVI, all ablation information was compared using Student's t-test and chi-square test for continuous and categorical variables, respectively. Univariate analysis was conducted on factors identified as significant by these methods; then, multivariate analysis with a logistic regression model was performed using the significant variables identified by univariate analysis to define an independent predictor of the gap area. We also assessed the points without Dmax $>6 \mathrm{~mm}$ and evaluated them in the same way. Receiver operating characteristic analysis was performed to determine the optimal cut-off value of Dmax that exhibited optimal sensitivity and specificity. The value for the maximum Youden index was considered as the optimal cut-off point. A P-value $<0.05$ was considered statistically significant. All statistical analyses were performed using EZR (Saitama Medical Center, Jichi Medical University, Saitama, Japan), a graphical user interface for R (The R Foundation for Statistical Computing, Vienna, Austria) designed to add statistical functions frequently used in biostatistics (10).

\section{Results}

\section{In vitro experiments}

In perpendicular contact (contact angle of $90^{\circ}$ ), lesion width was the smallest $(5.3 \pm 0.4 \mathrm{~mm}$ ) compared to $0^{\circ}$ (vs $5.8 \pm 0.5 \mathrm{~mm}, \mathrm{p}=0.040$ ) and $45^{\circ}$ (vs $6.4 \pm 0.4 \mathrm{~mm}, \mathrm{p}<0.001$ ), while lesion depth had no significant differences (Fig. 3). FTI and AI had no significant differences among the three groups (Table 1). As for generator impedance, both impedance drop and impedance before RF application were largest in $45^{\circ}$ (Table 1).

\section{Retrospective analysis of PVI}

Table 2 shows the baseline characteristics of the included patients. The overall patients included 22 men $(81.5 \%)$ with mean age of $60.7 \pm 9.4$ years. Ten patients $(37.0 \%)$ had paroxysmal AF. The mean period from the previous session was $358.4 \pm 202.4$ days. The LA-PV reconnections were detected in 21 ipsilateral PVs (38.9\%) in 16 patients (59.3\%). We assessed 666 tags of these 16 patients, and 60 tags were in the gap area. The left anterior carina area was the most frequent site of the gap area $(n=14)$, following the right posterior carina area $(\mathrm{n}=11)$, the right posterior superior area $(\mathrm{n}=8)$, and the left posterior superior area $(\mathrm{n}=5)$. The tags in the gap area had higher rate of perpendicular contact $(50.0 \%$ vs $16.7 \%, \mathrm{p}<0.001)$, longer Dmax $(6.9 \pm 1.8$ vs $5.9 \pm 1.5, \mathrm{p}<0.001)$, lower minimum CF $(2.3 \pm 3.5$ vs $4.8 \pm 5.1, \mathrm{p}<0.001)$, greater $\mathrm{CF}$ variability $(30.2 \pm 20.9$ vs $24.1 \pm 14.5, \mathrm{p}=0.003)$, lower FTI $(243.2 \pm 142.0$ vs $289.0 \pm 145.8, \mathrm{p}=0.020)$, higher ablation power, and lower impedance (maximum, minimum), although other variables, such as AI and impedance drop, showed no significant differences (Table 3). In the multivariate analysis, longer Dmax (OR 1.49, $\mathrm{p}<0.001$ ), larger CF variability (OR 1.03, $\mathrm{p}=0.008)$, and perpendicular contact (OR 3.26, $\mathrm{p}$ $<0.001$ ) were associated with the gap area (Table 3). Moreover, 19 of 381 points with Dmax [?]6 mm were detected in the gap area. In ablation points with Dmax [?]6 mm, larger CF variability (OR 1.05, $\mathrm{p}=0.005)$ and perpendicular contact (OR 3.47, $\mathrm{p}=0.025)$ were the predictors of PV reconnection on multivariate analysis (Table 4).

Table 5 shows the comparison between non-perpendicular $(\mathrm{n}=535)$ and perpendicular contact $(\mathrm{n}=131)$. Although maximum CF was significantly high in perpendicular contact than non-perpendicular contact (31.9 +- 21.9 vs $28.6+-14.8, \mathrm{p}<0.040)$, minimum $\mathrm{CF}$ was low $(2.2+-3.4$ vs $5.2+-5.2, \mathrm{p}<0.001)$, resulting 
in larger CF variability (29.8 +- 20.9 vs $23.4+-13.2, \mathrm{p}<0.001)$. As for generator impedance, perpendicular contact was associated with lower maximum and minimum impedance with lower impedance drop compared to non-perpendicular contact. Fig. 4 shows the common gap areas and the frequency of perpendicular contact in each area.

\section{Discussion}

To the best of our knowledge, this is the first study to assess the impact of catheter contact angle on RF lesion. The data shows that (I) the lesion size is small in perpendicular contact and (II) perpendicular contact is a strong predictor of the LA-PV reconnection in PVI.

\section{RF lesion created in different catheter contact angles}

In our in vitro study, although AI and FTI did not show significant differences among different catheter contact angles, the lesion width was small in the perpendicular contact and large in 45deg. We also found that initial impedance was significantly high in $45 \mathrm{deg}$.

In vitro experiments have shown that FTI or ablation index is known to be associated with lesion size $(11,12)$. However, AI and FTI do not consider contact angle at ablation sites that affect initial impedance, which in turn can influence lesion formation (13).

Lesions formed by RF application consist of two regions: a central region formed by resistive heating and a surrounding hemorrhagic region formed by conductive heat transfer that depends on application time. The lesion size influenced by resistive heating is determined by the amount of current delivered to the tissue (14). According to Joule's law, the amount of current is inversely proportional to the circuit impedance. Impedance represents resistance to current flow in the local tissue if other variables are under the same condition, including the RF generator, catheter, tissue distant to the heart, and return electrode, and in the general circuit cabling (15). The resistance of local tissue can be affected by tissue properties, catheter CF, or surface area covered by the catheter tip. In our study, as the catheter CF was fixed, lower impedance before ablation in perpendicular contact might be due to the narrower contact area between the catheter tip and myocardium, resulting in a small lesion.

\section{Factors of $\mathrm{LA}-\mathrm{PV}$ reconnection in PVI}

In our study, 38.9\% of PVs (21 of 54) in 16 of 27 patients (59.3\%) had PV reconnection in the repeat session. Univariate analysis showed several factors associated with PV reconnection: long interlesion distance; low minimum $\mathrm{CF}$; high $\mathrm{CF}$ variability; low initial, maximum, and minimum impedance; and perpendicular contact.

The importance of catheter CF has been investigated in studies examining the reconnection of segments in PVI line during AF ablation. EFFICAS I study has shown that PV reconnection at 3 months after PVI was strongly associated with minimum CF and minimum FTI at the site of gap (5). In EFFICAS II study, although the PV reconnection rates decreased following the CF guidance from EFFICAS I (target $20 \mathrm{~g}$, range $10-30 \mathrm{~g}$, minimum $400 \mathrm{~g} * \mathrm{STTI}), 15 \%$ of PV reconnections were still detected (6).

Catheter stability has been considered an important factor beyond FTI. Catheter stability was previously assessed using CF variability or relative standard deviation of CF. One in vitro study using a contractile bench model simulating the beating heart showed more variable contact resulting in smaller lesions (11). In the clinical study, Ullah et al. (9) demonstrated that lesions delivered with variability over $5 \mathrm{~g}$ are associated with a lower impedance drop, despite delivering the same FTI. They suggested that high degree of $\mathrm{CF}$ variability leads to a cooling effect on the tissue through stretching and unstretching, reducing the effect of ablation. Makimoto et al. (8) demonstrated that the relationship between the average and standard deviation of $\mathrm{CF}$ is correlated with acute PV reconnection. They show that ablation segments along the circumferential ablation lines delivered with lower average force and high variability are prone to form reconnection gaps. In our study, compared to non-perpendicular contact, larger maximum CF, lower minimum $\mathrm{CF}$, and larger CF variability during application were observed especially in perpendicular contact, 
indicating larger CF variability. Therefore, perpendicular contact can be an indicator of catheter instability leading to a nondurable lesion.

Interlesion distance is another important factor. A 'CLOSE' protocol ablation, targeting an interlesion distance [?] $6 \mathrm{~mm} \mathrm{AI} \mathrm{[?]400} \mathrm{and} \mathrm{[?]550} \mathrm{at} \mathrm{the} \mathrm{posterior} \mathrm{and} \mathrm{anterior} \mathrm{walls,} \mathrm{has} \mathrm{been} \mathrm{reported} \mathrm{with} \mathrm{better}$ outcome with lower PV reconnection and lower AF recurrence rate (7). In our study, 19 of 381 points with Dmax [?] $6 \mathrm{~mm}$ were still detected in the gap area. Once interlesion distance [?]6 $\mathrm{mm}$ was achieved, CF variability and perpendicular contact were the only two predictors of PV reconnection in the multivariate analysis. While the cut-off value of interlesion distance for PV reconnection in non-perpendicular contact was $6.2 \mathrm{~mm}$, the cut-off value in perpendicular contact was $5.2 \mathrm{~mm}$, which might reflect the smaller lesion size (Fig. 5). Therefore, strict target of interlesion distance might be necessary in perpendicular contact.

\section{Limitations}

Several limitations need to be underlined. An in vitro study was conducted under limited setting of CF, ablation time, and power. To avoid steam pop phenomenon, lower CF and lower power were selected compared with other in vitro studies $(11,12)$. The retrospective study is nonrandomized and has a small sample size. Further research in a large generalized population is needed.

\section{Conclusion}

Perpendicular contact was associated with smaller in vitro lesion size, and clinically, it was an indicator of catheter instability during PVI, resulting in nondurable lesion.

\section{References}

1. Hindricks G, Potpara T, Dagres N et al. 2020 ESC Guidelines for the diagnosis and management of atrial fibrillation developed in collaboration with the European Association of Cardio-Thoracic Surgery (EACTS). Eur Heart J 2020.

2. Murakawa Y, Nogami A, Shoda M et al. Nationwide Survey of Catheter Ablation for Atrial Fibrillation: The Japanese Catheter Ablation Registry of Atrial Fibrillation (J-CARAF). 2014;78:1091-1096.

3. Tzou WS, Marchlinski FE, Zado ES et al. Long-Term Outcome After Successful Catheter Ablation of Atrial Fibrillation. 2010;3:237-242.

4. Ouyang F, Antz M, Ernst S et al. Recovered Pulmonary Vein Conduction as a Dominant Factor for Recurrent Atrial Tachyarrhythmias After Complete Circular Isolation of the Pulmonary Veins. Circulation 2005;111:127-135.

5. Neuzil P, Reddy VY, Kautzner J et al. Electrical reconnection after pulmonary vein isolation is contingent on contact force during initial treatment: results from the EFFICAS I study. Circ Arrhythm Electrophysiol 2013;6:327-33.

6. Kautzner J, Neuzil P, Lambert $\mathrm{H}$ et al. EFFICAS II: optimization of catheter contact force improves outcome of pulmonary vein isolation for paroxysmal atrial fibrillation. Europace 2015;17:1229-35.

7. Phlips T, Taghji P, El Haddad M et al. Improving procedural and one-year outcome after contact forceguided pulmonary vein isolation: the role of interlesion distance, ablation index, and contact force variability in the 'CLOSE'-protocol. Europace 2018;20:f419-f427.

8. Makimoto H, Tilz RR, Lin T et al. Incidence and Anatomical Locations of Catheter Instability During Circumferential Pulmonary Vein Isolation Using Contact Force. International Heart Journal 2014;55:249-255.

9. Ullah W, Hunter RJ, Baker V et al. Factors affecting catheter contact in the human left atrium and their impact on ablation efficacy. J Cardiovasc Electrophysiol 2015;26:129-36.

10. Kanda Y. Investigation of the freely available easy-to-use software 'EZR' for medical statistics. Bone Marrow Transplantation 2013;48:452-458. 
11. Shah DC, Lambert H, Nakagawa H, Langenkamp A, Aeby N, Leo G. Area Under the Real-Time Contact Force Curve (Force-Time Integral) Predicts Radiofrequency Lesion Size in an In Vitro Contractile Model. Journal of Cardiovascular Electrophysiology 2010;21:1038-1043.

12. Mori H, Kato R, Sumitomo N et al. Relationship between the ablation index, lesion formation, and incidence of steam pops. Journal of Arrhythmia 2019.

13. Barkagan M, Rottmann M, Leshem E, Shen C, Buxton AE, Anter E. Effect of Baseline Impedance on Ablation Lesion Dimensions. Circulation: Arrhythmia and Electrophysiology 2018;11.

14. Eick OJ. Factors influencing lesion formation during radiofrequency catheter ablation. Indian Pacing Electrophysiol J 2003;3:117-28.

15. Bhaskaran A, Barry MA, Pouliopoulos J et al. Circuit Impedance Could Be a Crucial Factor Influencing Radiofrequency Ablation Efficacy and Safety: A Myocardial Phantom Study of the Problem and its Correction. J Cardiovasc Electrophysiol 2016;27:351-7.

Figure 1. Representative catheter position during radiofrequency application to Swine's heart (A) and the lesion (B).
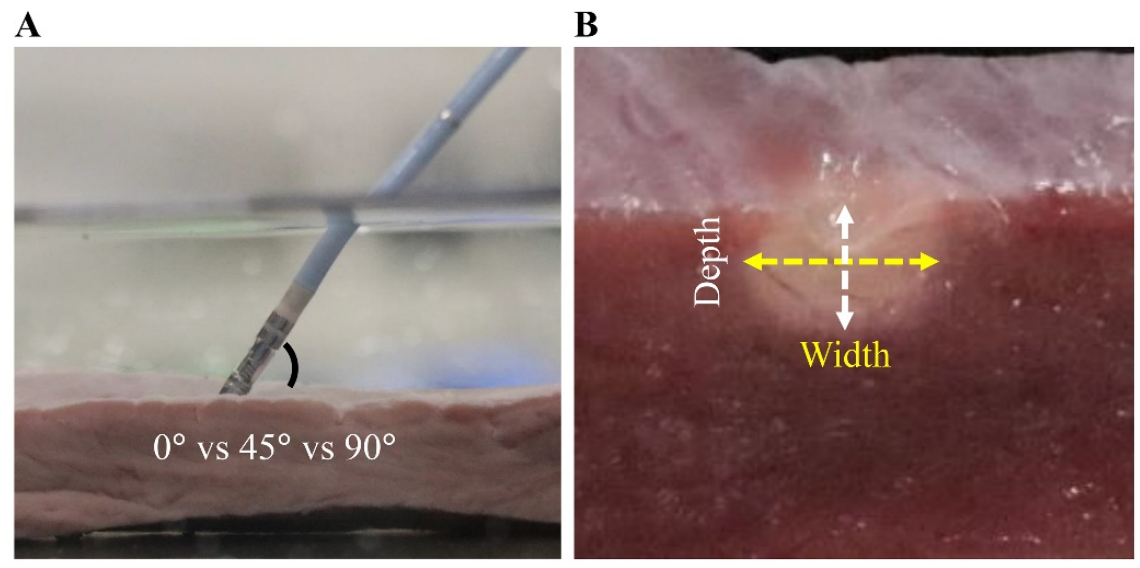

Figure 2. Representative VisiTags shown in the CARTO system.
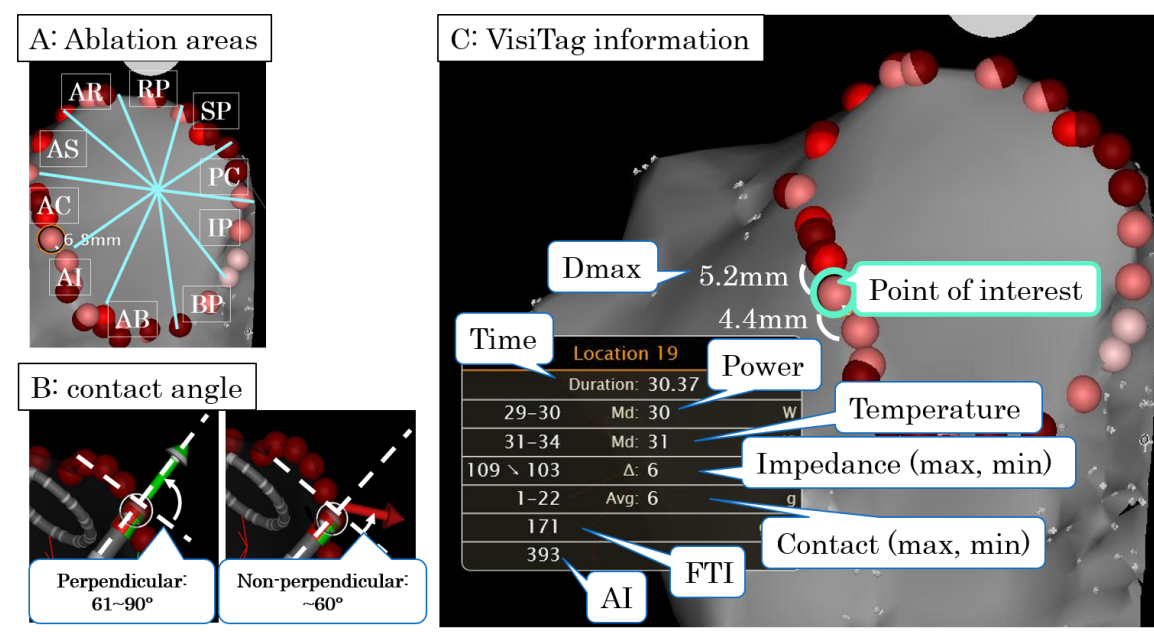

Ablation areas were divided into ten areas for each ipsilateral pulmonary vein (A). Ablation points were 
manually tagged to record the catheter position and the vector arrows showing actual angle of catheter tip to tissue. Perpendicular contact was defined when the angle between the vertical line to the ablation catheter and the vector arrow was $>60^{\circ}$ (B). Recorded VisiTag information (C). Dmax is the maximum distance to the adjacent tags.

$\mathrm{AR}$, anterior roof; $\mathrm{AS}$, anterior superior; $\mathrm{AC}$, anterior carina; $\mathrm{AI}$, anterior inferior; $\mathrm{AB}$, anterior bottom; $\mathrm{PR}$, posterior roof; PS, posterior superior; PC, posterior carina; PI, posterior inferior; PB, posterior bottom; FTI, force-time integral; AI, ablation index

Figure 3: Lesion widths (A) and depths (B) under different catheter contact angles

$\mathbf{A}$

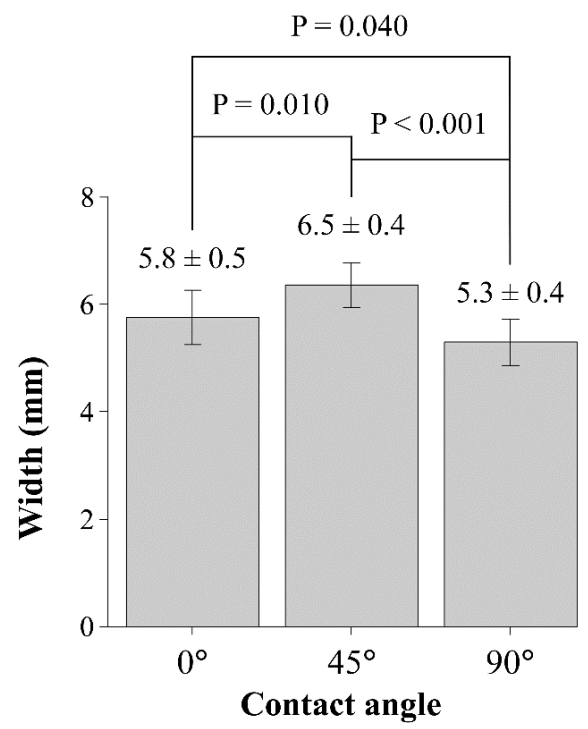

B

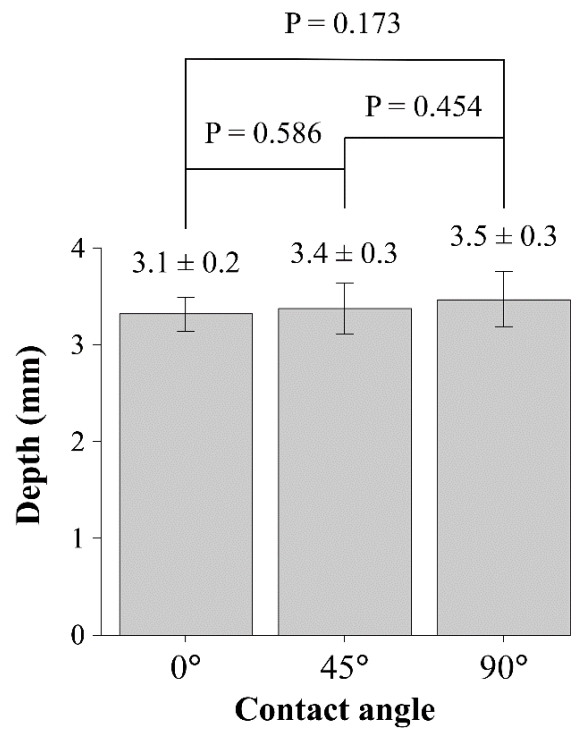

P-values were generated using Student's t-test.

Figure 4: The common gap areas and the frequency of perpendicular contact in each area
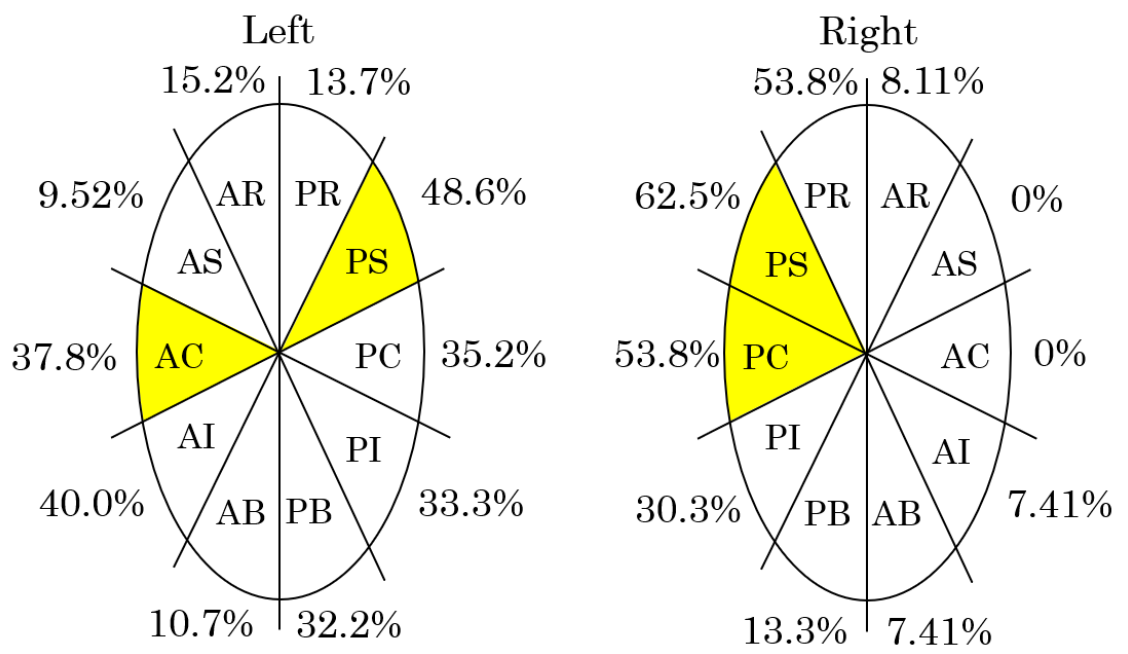

The common gap areas are highlighted, and the frequency of perpendicular contact is shown in each area. 
The most common gap area is the left carina anterior area $(\mathrm{n}=14)$, following the right carina posterior area $(n=11)$, the right posterior superior area $(n=8)$, and the left posterior superior area $(n=5)$. AR, anterior roof; AS, anterior superior; $\mathrm{AC}$, anterior carina; $\mathrm{AI}$, anterior inferior; $\mathrm{AB}$, anterior bottom; PR, posterior roof; PS, posterior superior; PC, posterior carina; PI, posterior inferior; PB, posterior bottom.

Figure 5: Receiver operating characteristic curve (ROC) for prediction of the gap area based on Dmax in non-perpendicular (A) and perpendicular contact (B)

A

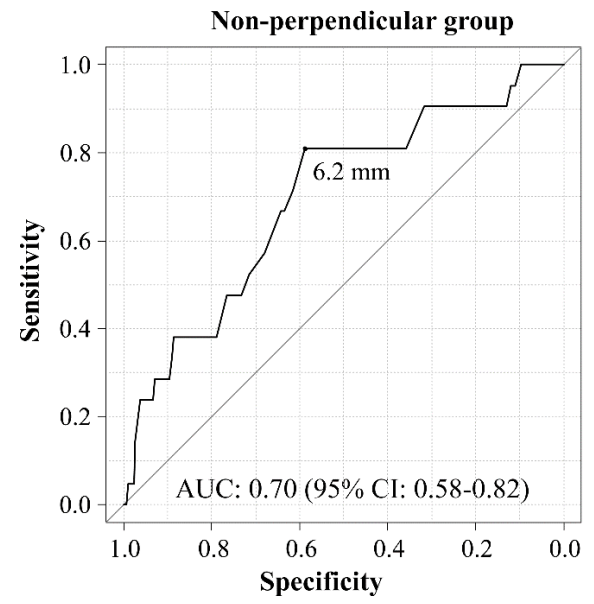

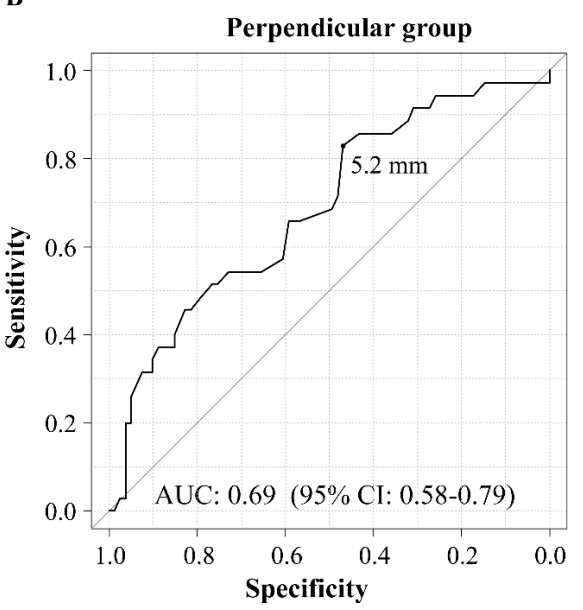

AUC, area under the curve; CI, confidence interval

Table 1. Ablation index (AI), force-time integral (FTI), and impedance information under different catheter contact angles

\begin{tabular}{|c|c|c|c|c|}
\hline & $0^{\circ} \mathrm{n}=10$ & $45^{\circ} \mathrm{n}=10$ & $90^{\circ} \mathrm{n}=10$ & P-value \\
\hline AI, mean $( \pm$ SD) & $292.20(28.48)$ & $295.80(23.22)$ & $299.70(25.51)$ & 0.811 \\
\hline FTI, g*s, mean $( \pm \mathrm{SD})$ & $216.40(84.70)$ & $226.80(72.43)$ & $239.70(80.25)$ & 0.807 \\
\hline$\Pi \rho \varepsilon-\imath \mu \pi \varepsilon \delta \alpha \nu \varsigma \varepsilon, \Omega, \mu \varepsilon \alpha \nu( \pm \Sigma \Delta)$ & $136.20(12.04)$ & $147.10(5.70)$ & $134.00(5.46)$ & 0.003 \\
\hline$\Pi о \sigma \tau-\iota \mu \pi \varepsilon \delta \alpha \nu \varsigma \varepsilon, \Omega, \mu \varepsilon \alpha \nu( \pm \Sigma \Delta)$ & $128.10(10.14)$ & $127.30(2.91)$ & $122.40(3.72)$ & 0.121 \\
\hline$I \mu \pi \varepsilon \delta \alpha \nu \varsigma \varepsilon \delta \rho \circ \pi, \Omega, \mu \varepsilon \alpha \nu( \pm \Sigma \Delta)$ & $8.10(3.48)$ & $19.80(4.89)$ & $11.60(2.59)$ & $<0.001$ \\
\hline
\end{tabular}

P-values were generated using one-way analysis of variance. AI, ablation index; FTI, force-time integral

Table 2. Baseline characteristics of the included patients

\begin{tabular}{|c|c|c|c|c|}
\hline $\begin{array}{l}\text { Baseline } \\
\text { characteristics }\end{array}$ & Overall $\mathrm{N}=27$ & Gap (-) $N=11$ & $\operatorname{Gap}(+) \mathbf{N}=16$ & P-value \\
\hline $\begin{array}{l}\text { Age } \\
\text { Sex }\end{array}$ & $60.7(9.4)$ & $58.9(7.5)$ & $62.0(10.6)$ & 0.411 \\
\hline Male, n (\%) & $22(81.5)$ & $9(81.8)$ & $13(81.2)$ & 1.000 \\
\hline $\begin{array}{l}\text { Female, } \mathbf{n}(\%) \\
\text { Type of atrial } \\
\text { fibrillation }\end{array}$ & $5(18.5)$ & $2(18.2)$ & $3(18.8)$ & \\
\hline $\begin{array}{l}\text { Persistent, } \mathbf{n} \\
(\%)\end{array}$ & $10(37.0)$ & $3(27.3)$ & $7(43.8)$ & 0.448 \\
\hline
\end{tabular}




\begin{tabular}{|c|c|c|c|c|}
\hline $\begin{array}{l}\text { Baseline } \\
\text { characteristics }\end{array}$ & Overall $\mathrm{N}=\mathbf{2 7}$ & $\operatorname{Gap}(-) \mathbf{N}=11$ & $\operatorname{Gap}(+) \mathbf{N}=16$ & $\mathrm{P}$-value \\
\hline $\begin{array}{l}\text { Paroxysmal, } \mathbf{n} \\
(\%)\end{array}$ & $17(63.0)$ & $8(72.7)$ & $9(56.2)$ & \\
\hline $\begin{array}{l}\text { Body mass } \\
\text { index, } \mathrm{kg} / \mathrm{m}^{2}, \\
\text { mean }( \pm \mathrm{SD})\end{array}$ & $1.8(0.2)$ & $1.9(0.2)$ & $1.8(0.2)$ & 0.217 \\
\hline $\begin{array}{l}\text { Congestive } \\
\text { heart failure, } \mathbf{n} \\
(\%)\end{array}$ & $8(29.6)$ & $5(45.5)$ & $3(18.8)$ & 0.206 \\
\hline $\begin{array}{l}\text { Diabetes } \\
\text { mellitus, n (\%) }\end{array}$ & $4(14.8)$ & $4(36.4)$ & $0(0.0)$ & 0.019 \\
\hline $\begin{array}{l}\text { Hypertension, } \\
\text { n (\%) }\end{array}$ & $17(63.0)$ & $7(63.6)$ & $10(62.5)$ & 1.000 \\
\hline Stroke, n (\%) & $4(14.8)$ & $2(18.2)$ & $2(12.5)$ & 1.000 \\
\hline $\begin{array}{l}\text { Coronary } \\
\text { artery disease, } \\
\text { n (\%) }\end{array}$ & $1(3.7)$ & $0(0.0)$ & $1(6.2)$ & 1.000 \\
\hline $\begin{array}{l}\text { CHADS }_{2} \text { score, } \\
\text { mean }( \pm \mathrm{SD})\end{array}$ & $1.4(1.3)$ & $1.8(1.2)$ & $1.2(1.4)$ & 0.226 \\
\hline $\begin{array}{l}\mathrm{CHA}_{2} \mathrm{DS}_{2^{-}} \\
\text {VASc score, } \\
\text { mean }( \pm \mathrm{SD})\end{array}$ & $2.0(1.7)$ & $2.3(1.6)$ & $1.8(1.8)$ & 0.449 \\
\hline $\begin{array}{l}\text { Left atrial } \\
\text { diameter, mm, } \\
\text { mean }( \pm \mathrm{SD})\end{array}$ & $42.8(8.3)$ & $45.7(8.1)$ & $40.8(8.1)$ & 0.133 \\
\hline $\begin{array}{l}\text { Left atrial } \\
\text { volume, } \mathrm{mL}, \\
\text { mean }( \pm \mathrm{SD})\end{array}$ & $81.9(28.7)$ & $86.7(33.4)$ & $78.4(25.3)$ & 0.480 \\
\hline $\begin{array}{l}\text { First-pass } \\
\text { isolation, } \mathrm{n}(\%)\end{array}$ & $13(48.1)$ & $6(54.5)$ & $7(43.8)$ & 0.688 \\
\hline
\end{tabular}

$\mathrm{CHADS}_{2}=$ congestive heart failure, 1 point; hypertension, 1 point; [?]75 years, 2 points; diabetes mellitus, 1 point; previous stroke, transient ischemic attack or thromboembolism, 2 points

CHA2DS2-VASc $=$ congestive heart failure, 1 point; hypertension, 1 point; [?]75 years, 2 points; diabetes mellitus, 1 point; previous stroke, transient ischemic attack or thromboembolism, 2 points; vascular disease, 1 point; $65-74$ years, 1 point; female sex, 1 point

Table 3. Comparison of radiofrequency ablation information of previous pulmonary vein isolation points between gap and no-gap area

\begin{tabular}{|c|c|c|c|c|c|}
\hline & $\begin{array}{l}\text { Gap }(-) \\
\mathbf{N}=606\end{array}$ & $\begin{array}{l}\text { Gap }(+) \\
\mathbf{N}=\mathbf{6 0}\end{array}$ & P-value & OR $(95 \% \mathrm{CI})$ & $\mathrm{P}$-value \\
\hline Temperature, ${ }^{\circ} \mathrm{C}$ mean $( \pm \mathrm{SD})$ & $33.3(2.7)$ & $33.1(1.9)$ & 0.523 & & \\
\hline Time, $s$, mean $( \pm S D)$ & $22.7(6.4)$ & $23.4(9.0)$ & 0.433 & & \\
\hline Power, W, mean ( \pm SD) & $25.4(3.8)$ & $26.5(4.1)$ & 0.029 & $1.08(1.00-1.18)$ & 0.056 \\
\hline Dmax, mm, mean $( \pm \mathrm{SD})$ & $5.9(1.5)$ & $6.9(1.8)$ & $<0.001$ & $1.49(1.26-1.76)$ & $<0.001$ \\
\hline Maximum CF, g, mean $( \pm \mathrm{SD})$ & $28.9(15.9)$ & $32.5(21.1)$ & 0.113 & & \\
\hline Minimum CF, g, mean ( \pm SD) & $4.8(5.1)$ & $2.3(3.5)$ & $<0.001$ & $0.92(0.81-1.04)$ & 0.170 \\
\hline CF variability, g, mean ( \pm SD) & $24.1(14.5)$ & $30.2(20.9)$ & 0.003 & $1.03(1.01-1.05)$ & 0.008 \\
\hline
\end{tabular}




\begin{tabular}{|c|c|c|c|c|c|}
\hline FTI, g*s, mean $( \pm$ SD $)$ & $289.0(145.8)$ & $243.2(142.0)$ & 0.020 & $1.00(1.00-1.00)$ & 0.296 \\
\hline $\mathrm{AI}$, mean $( \pm \mathrm{SD})$ & $376.9(56.2)$ & $376.1(59.7)$ & 0.915 & & \\
\hline 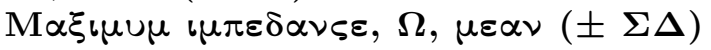 & $120.5(12.4)$ & $115.3(12.7)$ & 0.002 & $0.99(0.93-1.05)$ & 0.748 \\
\hline 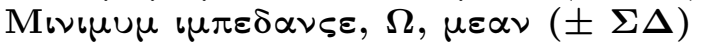 & $110.9(10.9)$ & $106.3(11.1)$ & 0.008 & $0.99(0.93-1.06)$ & 0.761 \\
\hline $\begin{array}{l}\text { I } \mu \pi \varepsilon \delta \alpha \nu \varsigma \varepsilon \delta \rho o \pi, \Omega, \mu \varepsilon \alpha \nu( \pm \Sigma \Delta) \\
\text { Contact angle, } n(\%)\end{array}$ & $10.3(5.7)$ & $8.9(4.5)$ & 0.058 & & \\
\hline Non-perpendicular & $505(83.3)$ & $30(50.0)$ & & - & - \\
\hline Perpendicular & $101(16.7)$ & $30(50.0)$ & $<0.001$ & $3.26(1.71-6.22)$ & $<0.001$ \\
\hline
\end{tabular}

P-values were generated using Student's t-test and chi-square test for continuous and categorical variables, respectively. Then, multivariate analysis with a logistic regression model was performed using the significant variables identified by univariate analysis to define an independent predictor of the gap area. Dmax is the maximum distance to the adjacent tags. CF, contact force; FTI, force-time integral; AI, ablation index

Table 4. Comparison of radiofrequency ablation information of previous pulmonary vein isolation points with maximum distance to the adjacent tags [?] $6 \mathrm{~mm}$ between gap and no-gap area

\begin{tabular}{|c|c|c|c|c|c|}
\hline & $\begin{array}{l}\text { Gap }(-) \\
\mathbf{N}=362\end{array}$ & $\begin{array}{l}\text { Gap }(+) \\
\mathbf{N}=19\end{array}$ & P-value & OR $(95 \% \mathrm{CI})$ & P-value \\
\hline Temperature, ${ }^{\circ} \mathrm{C}$, mean $( \pm \mathrm{SD})$ & $33.1(2.8)$ & $32.2(1.3)$ & 0.149 & & \\
\hline Time, s, mean $( \pm \mathrm{SD})$ & $22.2(5.9)$ & $21.5(5.0)$ & 0.621 & & \\
\hline Power, W, mean ( \pm SD) & $25.4(3.9)$ & $26.8(3.4)$ & 0.104 & & \\
\hline Dmax, mm, mean $( \pm$ SD $)$ & $5.0(0.8)$ & $5.0(0.7)$ & 0.897 & & \\
\hline Maximum CF, g, mean $( \pm \mathrm{SD})$ & $29.6(16.1)$ & $36.1(14.8)$ & 0.083 & & \\
\hline Minimum CF, g, mean ( \pm SD) & $4.7(5.3)$ & $1.8(2.0)$ & 0.019 & $0.94(0.73-1.20)$ & 0.598 \\
\hline CF variability, $g$, mean $( \pm S D)$ & $24.8(14.8)$ & $34.3(14.5)$ & 0.007 & $1.05(1.01-1.08)$ & 0.005 \\
\hline FTI, g*s, mean $( \pm \mathrm{SD})$ & $283.5(144.3)$ & $214.8(80.5)$ & 0.041 & $0.99(0.99-1.00)$ & 0.066 \\
\hline $\mathrm{AI}$, mean $( \pm \mathrm{SD})$ & $373.0(55.3)$ & $370.7(40.5)$ & 0.861 & & \\
\hline 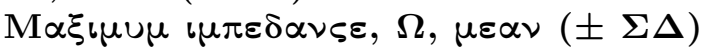 & $120.2(12.3)$ & $117.1(10.8)$ & 0.276 & & \\
\hline 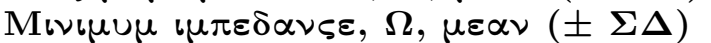 & $110.1(11.0)$ & $108.4(10.0)$ & 0.507 & & \\
\hline $\begin{array}{l}\text { I } \mu \pi \varepsilon \delta \alpha \nu \varsigma \varepsilon \delta \rho o \pi, \Omega, \mu \varepsilon \alpha \nu( \pm \Sigma \Delta) \\
\text { Contact angle, } \mathrm{n}(\%)\end{array}$ & $10.2(5.6)$ & $8.4(4.8)$ & 0.168 & & \\
\hline Non-perpendicular & $294(81.2)$ & $7(36.8)$ & & - & - \\
\hline Perpendicular & $68(18.8)$ & $12(63.2)$ & & $3.47(1.17-10.2)$ & 0.025 \\
\hline
\end{tabular}

P-values were generated using Student's t-test and chi-square test for continuous and categorical variables, respectively. Then, multivariate analysis with a logistic regression model was performed using the significant variables identified by univariate analysis to define an independent predictor of the gap area. Dmax is the maximum distance to the adjacent tags. CF, contact force; FTI, force-time integral; AI, ablation index

Table 5. Comparison of radiofrequency ablation information of previous pulmonary vein isolation points between parallel and perpendicular contact

\begin{tabular}{llll}
\hline & Non-perpendicular & Perpendicular & P-value \\
\hline & $\mathrm{N}=535$ & $\mathrm{~N}=131$ & \\
Tags within the gap area, n, (\%) & $30(5.6)$ & $30(23.0)$ & $<0.001$ \\
Temperature, ${ }^{\circ}$ C, mean $( \pm$ SD) & $33.4(2.7)$ & $33.1(2.0)$ & 0.279 \\
Time, s, mean ( \pm SD) & $22.7(6.5)$ & $23.0(7.2)$ & 0.657 \\
Power, W, mean $( \pm$ SD) & $25.5(3.8)$ & $25.7(4.0)$ & 0.563
\end{tabular}




\begin{tabular}{|c|c|c|c|}
\hline & Non-perpendicular & Perpendicular & P-value \\
\hline Dmax, mm, mean $( \pm \mathrm{SD})$ & $6.0(1.4)$ & $5.9(1.8)$ & 0.335 \\
\hline Maximum CF, g, mean ( \pm SD) & $28.6(14.8)$ & $31.9(21.9)$ & 0.040 \\
\hline Minimum CF, g, mean ( \pm SD) & $5.2(5.2)$ & $2.2(3.4)$ & $<0.001$ \\
\hline CF variability, g, mean ( \pm SD) & $23.4(13.2)$ & $29.8(20.9)$ & $<0.001$ \\
\hline FTI, g*s, mean $( \pm \mathrm{SD})$ & $298.2(145.0)$ & $230.3(137.2)$ & $<0.001$ \\
\hline AI, mean $( \pm \mathrm{SD})$ & $380.8(56.8)$ & $360.6(52.4)$ & $<0.001$ \\
\hline 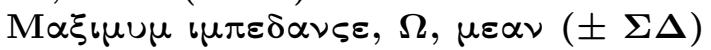 & $121.1(12.6)$ & $115.6(10.9)$ & $<0.001$ \\
\hline 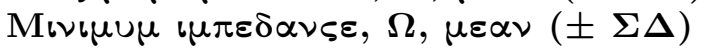 & $110.4(11.2)$ & $107.3(9.8)$ & 0.004 \\
\hline$I \mu \pi \varepsilon \delta \alpha \nu \varsigma \varepsilon \delta \rho o \pi, \Omega, \mu \varepsilon \alpha \nu( \pm \Sigma \Delta)$ & $10.7(5.8)$ & $8.3(4.4)$ & $<0.001$ \\
\hline
\end{tabular}

P-values were generated using Student's t-test and chi-square test for continuous and categorical variables, respectively. Dmax is the maximum distance to the adjacent tags. CF, contact force; FTI, force-time integral; AI, ablation index 